удК 338.242

В. М. Рыков

Байкальский государственный университет, 2. Иркутск, Российская Федеращия

Л. М. Дулина

Байкальский государственный университет, 2. Иркутск, Российская Федерация

\title{
СНИЖЕНИЕ ИНВЕСТИЦИОННОЙ АКТИВНОСТИ МАЛОГО И СРЕДНЕГО БИЗНЕСА В УСЛОВИЯХ КРИЗИСА
}

\begin{abstract}
АНнОТАЦИЯ. В статье рассматриваются особенности инвестиционной политики малого и среднего предпринимательства в условиях кризиса, исследованы темпы снижения кредитования малого и среднего бизнеса в Иркутской области. Анализируется динамика выдачи кредитов субъектам малого и среднего предпринимательства Приангарья, рост проблемной задолженности, отмеченный в течение в 2015 г. Рассматриваются альтернативные варианты инвестиционной политики в форме лизинга и микрозаймов. Автор отмечает, что в условиях кризиса на фоне общего экономического спада игроки финансового рынка расширяют инструментарий по работе с клиентами и предлагают выгодные условия для привлечения заемного капитала. Автор делает вывод, что снижение темпов инвестиционной активности на финансовом рынке значительно увеличивает экономические риски для субъектов малого и среднего бизнеса, но вместе с тем предоставляет дополнительные возможности для развития этих предприятий.

КЛЮЧЕВЫЕ СЛОВА. Инвестиции; кредиты; лизинг; объем инвестиций; темпы кредитования; малый и средний бизнес.

ИНФОРМАЦИЯ О СТАТЬЕ. Дата поступления 20 октября 2016 г.; дата принятия к печати 11 ноября 2016 г.; дата онлайн-размещения 30 ноября 2016 г.
\end{abstract}

V. M. Rykov Baikal State University, Irkutsk. Russian Federation

L. M. Dulina Baikal State University, Irkutsk. Russian Federation

\section{SLOWDOWN OF INVESTMENT ACTIVITY OF SMALL AND MID-SIZED BUSINESSES IN TERMS OF CRISIS}

ABSTRACT. The article considers the features of investment policy of small and midsized businesses in terms of crisis in Irkutsk Oblast. It analyses the dynamics of loan issue to subjects of small and mid-sized businesses in Lower Angara Region, the growth of troubled debts marked during 2015. It considers alternative variants of investment policy in form of leasing and microloans. The author notes that in terms of crisis against the background of the general economic slowdown the financial market players are expanding their tools in work with clients and offer favorable terms for attracting loan capital. The author makes a conclusion that the slowdown of investment activity rates considerably increases economic risks for subjects of small and mid-sized businesses and at the same time provides additional opportunities for developing such enterprises.

KEYWORDS. Investments; loans; leasing; amount of investments; rates of crediting; small and mid-sized business.

ARTICLE INFO. Received October 20, 2016; accepted November 11, 2016; available online November 30, 2016.

(c) В. М. Рыков, Л. М. Дулина, 2016

\section{Baikal Research Journal}


Современные экономические условия стали настоящим испытанием для всех без исключения организаций малого и среднего бизнеса. Риски неполучения запланированной прибыли, угроза убытков, сокращение объемов производимых товаров (работ, услуг) на фоне общего снижения покупательского спроса, высокого уровня инфляции, изменчивости курса валюты - все это заставляет собственников бизнеса и управленцев отказываться от финансирования инвестиционных проектов, выстраивать стратегию выживания и сохранения имеющихся темпов работы, искать пути решения преодоления возникших трудностей в условиях неопределенности.

По информации Росстата объем вливаний в основной капитал сократился по сравнению с предыдущим годом на $8,4 \%{ }^{1}$. Компании стали экономить на инвестициях в основные фонды. В дальнейшем это может привести к неожиданным срывам поставок, сокращению объемов выпускаемой продукции, аварийным ситуациям, в конечном итоге затормаживанию развития предприятия. $K$ проблеме развития коммерческих организаций в период кризиса обращаются современные экономисты Г. Ю. Билыч [1], Н. Г. Кизян [2], Р. Зиннуров [3], в своих работах они описывают основные направления развития предприятий, на которых сегодня сосредоточен антикризисный менеджмент.

Экономия на основных фондах - вынужденная мера, в условиях кризиса предприниматели традиционно начинают путь оздоровления бизнеса с сокращения затрат. Это касается также производственного процесса, взаимоотношений с поставщиками: уменьшение операционных расходов, удлинение товарных кредитов, реструктуризация имеющихся долгов. В условиях острой нехватки оборотных средств компании привлекают заемные средства, однако сталкиваются с ограниченным доступом к инвестициям, со сложностями в получении кредитов и подорожанием кредитных продуктов. По признанию экспертов, сложившийся на сегодняшний день уровень инвестиционной активности не обеспечивают бизнесу переход к устойчивому росту - на это обращают внимание в своих исследованиях современных экономических условий В. Миронов [4; 5], Т. Б. Полторацкая [6], А. П. Родионов [7], Л. В. Санина [8].

В конце 2015 г. средняя ставка по кредитам для малого бизнеса в самом распространенном сегменте «от 1 до 3 лет» была на уровне $21 \%$. За последних три месяца года она увеличилась на $3 \%^{2}$. Наряду с высокими издержками по обслуживанию заемных средств предприниматели столкнулись с введением ограниченных лимитов и невозможностью получения займов у банков. Большинство банков столкнулось с ростом проблемных активов, количество просроченных кредитов увеличилось, поэтому банки повысили требования к заемщикам и сократили беззалоговое кредитование.

Объем просроченной задолженности по кредитам, выданным субъектам малого и среднего предпринимательства, по информации Центрального банка Российской Федерации увеличился более чем в полтора раза: с 378,75 млрд р. в 2014 г. до 632,93 млрд р. в 2015 г. $^{3}$ Такая же тенденция наблюдается и в предпринимательской среде Иркутской области, сумма просроченной задолженности по выданным кредитам среди субъектов малого и среднего бизнеса Приангарья за минувший год составила 5,5 млрд р. - это почти восьмая часть суммы общей кредитной задолженности. Годом ранее это соотношение равнялось одному к двадцати, т. е. из 64,99 млрд р. общей суммы кредитов, выданных малым и средним компаниям Иркутской области, только 3,2 млрд р. относились к проблемным обязательствам.

\footnotetext{
${ }^{1}$ Федеральная служба государственной статистики : офиц. сайт. URL: http://www.gks.ru.

${ }^{2}$ Центральный банк Российской Федерации : офиц. сайт. URL: http://www.cbr.ru.

${ }^{3}$ URL: http://www.cbr.ru.
}

\section{Baikal Research Journal}


В целом объем выданных кредитов предприятиям малого и среднего бизнеса Иркутской области по данным Центрального банка РФ сократился в 2015 г. на $44 \%$, если по итогам 2014 г. малым и средним компаниям нашего региона было выдано 100,53 млрд р., то в 2015 г. только 56,27 млрд р. Такие темпы снижения инвестиционной активности наблюдаются и в целом по стране: объем кредитов сегмента малого и среднего бизнеса сократился по сравнению с предыдущим годом более чем на 2 трлн р., т.е. почти на $30 \%$. Темпы кредитования субъектов малого и среднего предпринимательства за последние три года представлены в таблице. Стоит отметить, что, не смотря на общее снижение объемов кредитования, в сегменте выданных кредитных средств в иностранной валюте наблюдается активность. Так, за 2015 г. объем выданных кредитов в иностранной валюте предпринимателям Приангарья увеличился в пять раз, с 1,58 млрд р. в 2014 г. до 8,53 млрд р. в 2015 г., и это не смотря на ухудшение экономических условий и сохраняющуюся неопределенность в поведении валютного курса. Нельзя говорить о сохраняющейся тенденции в этом году, по данным прошедших шести месяцев иркутские предприниматели не воспользовались кредитными средствами в иностранной валюте. Исключая вероятность наступления неблагоприятных финансовых последствий, учитывая неопределенность курса рубля, предприниматели стремятся снизить операционные валютные риски и отказываются от заемных средств в иностранной валюте.

Объем кредитов, предоставленных субъектам малого и среднего бизнеса в рублях, иностранной валюте, драгоценных металлах в 2013-2015 г2., млн р.

\begin{tabular}{|c|c|c|c|c|c|c|c|c|c|c|}
\hline \multirow{2}{*}{$\begin{array}{c}\text { Объем кредитов } \\
\text { субъектам ма- } \\
\text { лого и среднего } \\
\text { бизнеса }\end{array}$} & \multicolumn{2}{|c|}{2013} & \multicolumn{2}{|c|}{2014} & \multicolumn{2}{|c|}{$\begin{array}{cc}\% & 2014 \\
\text { к } 2013\end{array}$} & \multicolumn{2}{|c|}{2015} & \multicolumn{2}{|c|}{$\begin{array}{l}\% 2015 \\
\text { К } 2014\end{array}$} \\
\hline & \begin{tabular}{|c|} 
Ир- \\
кут- \\
ская \\
об- \\
ласть \\
\end{tabular} & $\begin{array}{l}\text { Россий- } \\
\text { ская Фе- } \\
\text { дерация }\end{array}$ & $\begin{array}{l}\text { Иркут- } \\
\text { ская } \\
\text { область }\end{array}$ & $\begin{array}{l}\text { Россий- } \\
\text { ская Фе- } \\
\text { дерация }\end{array}$ & \begin{tabular}{|c|} 
Ир- \\
кут- \\
ская \\
об- \\
ласть
\end{tabular} & \begin{tabular}{|l|} 
Рос- \\
сий- \\
ская \\
Феде-- \\
рация
\end{tabular} & $\begin{array}{c}\text { Ир- } \\
\text { кут- } \\
\text { ская } \\
\text { об- } \\
\text { ласть }\end{array}$ & $\begin{array}{l}\text { Россий- } \\
\text { ская Фе- } \\
\text { дерация }\end{array}$ & $\begin{array}{c}\text { Ир- } \\
\text { кут- } \\
\text { ская } \\
\text { об- } \\
\text { ласть }\end{array}$ & $\begin{array}{l}\text { Рос- } \\
\text { сий- } \\
\text { ская } \\
\text { Феде- } \\
\text { рация }\end{array}$ \\
\hline В рублях & 78900 & 7761530 & 100526 & 7194839 & 27,4 & $-7,3$ & 56271 & 5080951 & $-44,0$ & $-29,4$ \\
\hline $\begin{array}{l}\text { В том числе } \\
\text { индивидуаль- } \\
\text { ным предпри- } \\
\text { нимателям }\end{array}$ & 14436 & 688022 & 13581 & 579638 & $-5,9$ & $-15,8$ & 5354 & 307425 & $-60,6$ & $-47,0$ \\
\hline $\begin{array}{l}\text { В иностранной } \\
\text { валюте }\end{array}$ & 224 & 303229 & 1575 & 415755 & 603,1 & 37,1 & 8531 & 379322 & 441,7 & $-8,8$ \\
\hline $\begin{array}{l}\text { В том числе } \\
\text { индивидуаль- } \\
\text { ным предпри- } \\
\text { нимателям }\end{array}$ & 158 & 3006 & 27 & 2944 & $-82,9$ & $-2,1$ & 0 & 822 & $-100,0$ & $-72,1$ \\
\hline Всего & 79124 & 8064759 & 102101 & 7610594 & 29,0 & $-5,6$ & 64802 & 5460273 & $-36,5$ & $-28,3$ \\
\hline $\begin{array}{l}\text { В том чис- } \\
\text { ле индиви- } \\
\text { дуальным } \\
\text { предприни- } \\
\text { мателям }\end{array}$ & 14594 & 691028 & 13608 & 582582 & $-6,8$ & $-15,7$ & 5354 & 308247 & $-60,7$ & $-47,1$ \\
\hline
\end{tabular}

По данным рейтингового агентства «Эксперт РА» ${ }^{4}$ целом объем выданных кредитов малому и среднему бизнесу по итогам полугодия 2016 г. сохранился примерно на уровне прошлого года. Причем значительную роль в этом сыграли крупные банки, проводящие более строгий контроль заемщиков и более пристально оценивающие финансовое состояние предприятий, обращающихся за заемным капиталом. В результате чего не произошло и увеличения доли просроченных кре-

${ }^{4}$ URL: http://www.raexpert.ru.

\section{Baikal Research Journal}

электронный научный журнал Байкальского государственного университета 
дитов, не смотря на сложную ситуацию на рынке, когда, в особенности, небольшие компании испытывают острый дефицит оборотных средств. Если в прошлом году объем просроченных выплат по кредитам составлял 40 \% среди субъектов малого и среднего предпринимательства, - то по результатам шести месяцев этого года этот показатель снизился до $28 \%$.

Во втором квартале текущего года наблюдался небольшой прирост по объемам выдачи кредитов малому и среднему бизнесу: по сравнению тем же периодом 2015 г. на $2 \%$, по итогам первого полугодия банки выдали малому и среднему бизнесу 2,4 трлн р. ${ }^{5}$ Не смотря на положительную динамику в целом и сохранение объемов кредитования следует отметить, что для самих представителей небольших компаний, обращающихся за кредитами, ситуация не выглядит настолько же оптимистичной. По информации «Эксперт РА» объем кредитных заявок в этом году увеличился вдвое, а это значит, что около половины компаний получили отказы от банков.

Такие темпы кредитования малого бизнеса сохранятся до конца года - утверждают эксперты, принимая во внимание тенденцию к сохранению ключевой ставки, а, по мнению отдельных специалистов, даже ее незначительному снижению.

Выгодной альтернативой кредиту в условиях экономической нестабильности и неопределенности становится лизинговое финансирование, для компаний это эффективный финансовый рычаг в управлении. Исследуя динамику развития рынка лизинга Р. Коршунов, Р. Романовский, С. Волков в своем отчете отмечают, что на фоне падения спроса лизинговые агенты стали предлагать выгодные условия предоставления лизинговой аренды [9]. Компании получили возможность развития, обновления основных фондов за счет приобретения нового технологического оборудования, автомобилей и спецтехники, объектов недвижимости. В общей объеме лизинговых сделок за 2015 г. 44 \% приходится на долю малого и среднего бизнеса. По данным агентства «Эксперт РА» объем «нового бизнеса» (вновь заключенные договоры) в сегменте малого и среднего бизнеса в 2015 г. составил 281 млрд р., в 2014 г. этот показатель был равен 321 млрд р., таким образом, объем лизингового финансирования сократился на 12,5 \% . Между тем, эксперты отмечают, что рынок финансирования малого и среднего бизнеса оказался более устойчив - падение на рынке в целом составило $20 \%$. Интерес малого и среднего бизнеса стимулировала льготная программа автолизинга, позволившая предпринимателем приобретать транспортные средства на выгодных условиях. Стремясь сохранить клиентов и привлечь новых, лизингодатели предоставляли скидки, вводили новые экспресс-продукты. В итоге сегмент автолизинга сократился на $18 \%$, сохранив значительную долю, более $30 \%$, рынка [10]. По оценкам специалистов лизинговый портфель, показавший отрицательный результат по итогам прошлого года, замедлит темпы падения, но не выйдет на докризисный уровень.

В рамках финансирования малого бизнеса одним из перспективных направлений является работа с микрофинансовыми организациями и институтами. Микрофинансовые организации, созданные при государственном участии, в рамках программы поддержки малого и среднего предпринимательства, оказывают ощутимую финансовую помощь малому бизнесу. Ставка на уровне $10 \%$ позволяет компаниям привлекать заемные средства, фактически, в рассрочку, перекрывая инфляционные издержки. Таким образом, компании получают больше возможностей для развития. При неравнодушном отношении к сегменту малого бизнеса со стороны государства экономических эффект, выраженный не столько в финансовых показателях, сколько в социальной отдаче от принятых мер особенно значим

\footnotetext{
${ }^{5}$ Кредитование малого и среднего бизнеса России: итоги 1 полугодия 2016 года. URL: http:// www.raexpert.ru/researches/banks/msb_1h2016.
}

\section{Baikal Research Journal}


в период экономической нестабильности, об этом в своих научных выступлениях в том числе говорят А. Мурзина [11] и О. В. Чистякова [12].

Специалисты отмечают, что в сегодняшних условиях банки и лизингодатели как никогда готовы работать с малым бизнесом. Банки уходят от консервативного подхода в работе с небольшими компаниями и предлагают сегодня различные варианты кредитования. Новые кредитные продукты, ориентированные на представителей малого бизнеса, учитывают особенности формирования выручки фирмы, сезонность отдельных направлений деятельности компании, специфику работы с отдельными заказчиками, идут навстречу в случае вынужденных простоев в работе. Лизингодатели предлагают экспресс-продукты, предоставляют скидки, удлиняют срок финансовой аренды. Таким образом, не смотря на кажущуюся бесперспективность внешнего финансирования, малый и средний бизнес в период кризиса имеет достаточный набор инвестиционных инструментов. Однако мероприятия по привлечению инвестиций должны проводиться системно, в совокупности с другими методами финансового оздоровления компании: совместно с работой с кредиторской и дебиторской задолженностью, инвентаризацией, распродажей запасов, оптимизацией затрат, управлением организационными процессами. Сознательная и реальная оценка состояния компании, совершенствование уровня организации, контроль за расходами, финансовое планирование позволят снизить потенциальные риски и предотвратить возможности получение убытков или недополучения прибыли в условиях экономической нестабильности.

\section{Список использованной литературы}

1. Билыч Г. Ю. Экономическая динамика. Кризис как состояние экономического равновесия [Электронный ресурс] / Г. Ю. Билыч. - Режим доступа: http://sbiblio.com/biblio/ archive/bili_ekon/.

2. Кизян Н. Г. Направления развития предприятий в условиях кризиса / Н. Г. Кизян, Е. В. Мелякова // Проблемы современной экономики. - 2015. - № 4 (56). - С. 110-112.

3. Зиннуров Руслан. Рисками надо управлять грамотно [Электронный ресурс] : интервью / записала Т. Криницкая // Бизнес-журнал. - 2016. - 11 марта. - Режим доступа: http://b-mag.ru/2016/finance/ruslan-zinnurov-riskami-nado-upravlyat-gramotno.

4. Миронов В. Об инвестиционной активности как факторе возобновления экономического роста [Электронный ресурс] / В. Миронов, А. Кузнецов // Комментарии о государстве и бизнесе. - 2016. - № 120. - Режим доступа: https://dcenter.hse.ru/ data/2016/09/16/1123548107/rs_16-16.pdf.

5. Миронов В. Нынешний уровень и структура инвестиционной активности не обеспечивают перехода к устойчивому росту [Электронный ресурс] / В. Миронов // Комментарии о Государстве и Бизнесе. - 2016. - № 115. - Режим доступа: https://dcenter.hse.ru/ data/2016/06/22/1116178898/rs_16-11.pdf.

6. Полторацкая Т. Б. Статистическая оценка предложения кредитных ресурсов в реальном секторе экономики для малого и среднего бизнеса / Т. Б. Полторацкая // Проблемы современной экономики. - 2016. - № 2 (58). - С. 101-104.

7. Родионов А. П. Проблемы и перспективы развития малого предпринимательства строительной отрасли на современном этапе / А. П. Родионов // Проблемы современной экономики. - 2016. - № 2 (58). - С. 120-23.

8. Санина Л. В. Проблемы и перспективы оказания финансовой поддержки субъектам малого и среднего предпринимательства Иркутской области [Электронный ресурс] / Л. В. Санина // Известия Иркутской государственной экономической академии (Байкальский государственный университет экономики и права). - 2014. - № 1. - Режим доступа: http://brj-bguep.ru/reader/article.aspx?id=18738.

9. Коршунов Р. Рынок лизинга по итогам 2015 года: на субсидиях [Электронный ресурс] : обзор / Р. Коршунов, Р. Романовский, С. Волков. - Режим доступа: http://www. ulk.ru/downloads/file/bull_leasing_itogi_2015.pdf.

\section{Baikal Research Journal}


10. Кушнир Н. Автолизинг: пан или тоже пропал? [Электронный ресурс] / Н. Кушнир. - Режим доступа: http://www.all-leasing.ru/analitic/detail/1009527.

11. Мурзина А. Малый бизнес: популярный, перспективный, но неизведанный [Электронный ресурс] / А. Мурзина. - Режим доступа: http://raexpert.ru/editions/ article20.

12. Чистякова О. В. Современные аспекты государственной поддержки малого и среднего предпринимательства / О. В. Чистякова // Известия Иркутской государственной экономической академии. — 2013. - № 4 (90). — С. 65-69.

\section{References}

1. Bilych G. Yu. Ekonomicheskaya dinamika. Krizis kak sostoyanie ekonomicheskogo ravnovesiya [Economic dynamics. Crisis as a state of economic balance]. Available at: http:// sbiblio.com/biblio/archive/bili_ekon/. (In Russian).

2. Kizyan N. G., Melyakova E. V. Development of enterprises in the context of crisis. Problemy sovremennoi ekonomiki $=$ Problems of Modern Economics, 2015, no. 4 (56), pp. 110-112. (In Russian).

3. Zinnurov Ruslan; Krinitskaya T. (ed). Risks must managed correctly. Business journal, 2016, March 11. Available at: http://b-mag.ru/2016/finance/ruslan-zinnurov-riskami-nado-upravlyat-gramotno. (In Russian).

4. Mironov V., Kuznetsov A. On investment activity as a factor of economic growth renewal. Kommentarii o Gosudarstve $i$ Biz-nese $=$ Comments on State and Business, 2016, no. 120. Available at: https://dcenter.hse.ru/data/2016/09/16/1123548107/rs_16-16.pdf. (In Russian).

5. Mironov V. Current level and investment activity structure do not provide transition to stable growth. Kommentarii o Gosudarstve $i$ Biznese $=$ Comments on State and Business, 2016, no. 115. Available at: https://dcenter.hse.ru/data/2016/06/22/1116178898/rs_16-11. pdf. (In Russian).

6. Poltoratskaya T. B. Statistic evaluation of credit resource supply in the real sector of economy for small- and medium scale business. Problemy sovremennoi ekonomiki $=$ Problems of Modern Economics, 2016, no. 2 (58), pp. 101-104. (In Russian).

7. Rodionov A. P. Current problems and perspectives of small-scale entrepreneurship in Russia's construction industry. Problemy sovremennoi ekonomiki = Problems of Modern Economics, 2016, no. 2 (58), pp. 120-123. (In Russian).

8. Sanina L. V. Problems and prospects of financial support for small and medium business in Irkutsk oblast. Izvestiya Irkutskoi gosudarstvennoi ekonomicheskoi akademii (Baykalskii gosudarstvennyi universitet ekonomiki i prava) = Bulletin of Irkutsk State Economics Academy (Baikal State University of Economics and Law), 2014, no. 1. Available at: http://brj-bguep. $\mathrm{ru} /$ reader/article.aspx?id=18738. (In Russian).

9. Korshunov R., Romanovsky R., Volkov S. Rynok lizinga po itogam 2015 goda: na sub sidiyakh: obzor [Leasing market based on the results of 2015: in terms of subsidies: review]. Available at: http://www.ulk.ru/downloads/file/bull_leasing_itogi_2015.pdf. (In Russian).

10. Kushnir N. Avtolizing: pan ili tozhe propal? [Autoleasing: double or also nothing? Available at: http://www.all-leasing.ru/analitic/detail/1009527. (In Russian).

11. Murzina A. Malyi biznes: populyarnyi, perspektivnyi, no neizvedannyi [Small business: popular, promising, but unknown]. Available at: http://raexpert.ru/editions/ article20. (In Russian).

12. Chistyakova O. V. The modern aspects of governmental support for small and medium-sized entrepreneurship. Izvestiya Irkutskoi gosudarstvennoi ekonomicheskoi akademii = Bulletin of Irkutsk State Economics Academy, 2013, no. 4 (90), pp. 65-69. (In Russian).

\section{Информация об авторах}

Рыков Виктор Михайлович - доктор экономических наук, профессор, кафедра экономики предприятий и предпринимательской деятельности, Байкальский государственный университет, 664003, г. Иркутск, ул. Ленина, 11, e-mail: keppd@bgu.ru.

Дулина Людлила Михайловна - магистрант, кафедра экономики предприятий и предпринимательской деятельности, Байкальский государственный университет, 664003, г. Иркутск, ул. Ленина, 11, e-mail: dulinal@mail.ru.

\section{Baikal Research Journal}




\section{Authors}

Viktor M. Rykov - Doctor habil. (Economics), Professor, Chair of Bisiness Economy and Entrepreneurial Activity, Baikal State University, 11 Lenin St., 664000, Irkutsk, Russian Federation; e-mail: keppd@bgu.ru.

Lyudmila M. Dulina - Master Degree Student, Chair of Bisiness Economy and Entrepreneurial Activity, Baikal State University, 11 Lenin St., 664000, Irkutsk, Russian Federation; e-mail: dulinal@mail.ru.

\section{Библиографическое описание статьи}

Рыков В. М. Снижение инвестиционной активности малого и среднего бизнеса в условиях кризиса / В. М. Рыков, Л. М. Дулина // Baikal Research Journal. — 2016. — T. 7, № 6. - DOI: 10.17150/2411-6262.2016.7(6).11.

\section{Reference to article}

Rykov V. M., Dulina L. M. Slowdown of investment activity of small and mid-sized businesses in terms of crisis. Baikal Research Journal, 2016, vol. 7, no. 6. DOI: 10.17150/24116262.2016.7(6).11. (In Russian).

\section{Baikal Research Journal}

